\title{
Viscosities of oxalic acid and its salts in water and binary aqueous mixtures of tetrahydrofuran at different temperatures
}

\author{
M L PARMAR* and M K GULERIA \\ Department of Chemistry, Himachal Pradesh University, Summer Hill, Shimla 171 005, India
}

MS received 9 November 2004; revised 21 March 2005

\begin{abstract}
Relative viscosities for the solutions of oxalic acid and its salts, viz. ammonium oxalate, sodium oxalate and potassium oxalate, at different concentrations have been determined in water and in binary aqueous mixtures of tetrahydrofuran (THF) [5, 10, 15 and $20 \%$ by weight of THF] at $298 \cdot 15 \mathrm{~K}$, and in water and in $5 \%(\mathrm{w} / \mathrm{w}) \mathrm{THF}+$ water at five different temperatures. The data have been evaluated using the Jones-Dole equation and the obtained parameters have been interpreted in terms of solute-solute and solute-solvent interactions. The activation parameters of viscous flow have been obtained which depicts the mechanism of viscous flow. The oxalic acid and its salts behave as structure breakers in water and in binary aqueous mixtures of THF.
\end{abstract}

Keywords. Viscosities; oxalic acid and its salts; water + THF mixtures; structure-breakers.

\section{Introduction}

Studies on viscosities of ionic solutions are of great help in characterizing the structure and properties of solutions. Various types of interactions exist between the ions in the solutions and of these, ion-ion and ion-solvent interactions are of current interest in all the branches of chemistry. These interactions help in better understanding of the nature of solute and solvent, i.e. whether the solute modifies or distorts the structure of the solvent. The solution structure is of great importance in understanding the nature of bioactive molecules in the body system. The survey of literature ${ }^{1-20}$ show that although many studies have been carried out for various electrolytic solutions, little attention has been paid to the behaviour of oxalic acid and its salts in water and in water + THF mixtures. Such data are expected to highlight the role of oxalic acid and its salts in influencing the viscosity $B$-coefficient, in water and in mixed solvent systems.

Tetrahydrofuran (THF), commercially known as cellosolves, is a good industrial solvent. It figures prominently in the high energy battery industry and has found its application in the organic syntheses as manifested from physico-chemical studies in this medium. ${ }^{21} \mathrm{THF}+\mathrm{H}_{2} \mathrm{O}$ mixtures are also important

*For correspondence owing to $\mathrm{H}$-bonding between water and tetrahydrofuran. Hence, the present investigation has been undertaken to provide better understanding of the nature of these solutes in water and in THF + water system and to throw light on solute-solvent interactions.

\section{Materials and methods}

Oxalic acid, ammonium oxalate, sodium oxalate and potassium oxalate (all of Analytical Reagent grade) were used after drying over $\mathrm{P}_{2} \mathrm{O}_{5}$ in a desiccator for more than $24 \mathrm{~h}$. The reagents were always placed in the desiccator over $\mathrm{P}_{2} \mathrm{O}_{5}$ to keep them in dry atmosphere. Freshly distilled conductivity water (sp. cond. $\approx 10^{-6} \mathrm{ohm}^{-1} \mathrm{~cm}^{-1}$ ) was used for preparing binary aqueous mixtures of THF as well as standard liquid. Tetrahydrofuran of AnalaR grade was kept over calcium hydride for about $24 \mathrm{~h}$ and then decanted and distilled under reduced pressure. The first and last fractions were discarded and only the middle fraction was collected for the present study. Density and viscosity of THF were found to be $0.8810 \mathrm{~g} \mathrm{~cm}^{-3}$ and $0.461 \mathrm{cP}$ respectively at $298 \mathrm{~K}$ and are in good agreement with the literature values ${ }^{22}\left(0.8811 \mathrm{~g} \mathrm{~cm}^{-3}\right.$ and $0.460 \mathrm{cP})$.

All the binary aqueous mixtures of THF as well as the solutions of oxalic acid and its salts were made by weight and molalities, $m$, were converted into molarities, $c$, using the standard expression ${ }^{23}$ : 
$c=1000 \mathrm{~d} \mathrm{~m} /\left(1000+m M_{2}\right)$, where $d$ is the solution density and $M_{2}$ the molecular weight of an solute.

For density measurements, an apparatus similar to the one reported by Ward and Millero ${ }^{24}$ and described elsewhere ${ }^{25}$ was used. The accuracy in density measurement was of $\pm 1 \cdot 10^{-5} \mathrm{~g} \mathrm{~cm}^{-3}$. The relative viscosities were measured at the desired temperature using Ostwald's suspended level type viscometer with a flow time of $375 \mathrm{~s}$ for water at $298 \mathrm{~K}$. Runs were repeated until three successive determinations were obtained within $\pm 0 \cdot 1 \mathrm{~s}$. Since all the flow times were greater than $100 \mathrm{~s}$, kinetic energy correction was not necessary. The relative viscosities of the solutions $\left(\eta_{\text {rel }}\right)$ were calculated by the usual procedure. $^{26,27}$ Density and viscosity measurements were carried out in a well-stirred water-bath whose temperature was controlled to $\pm 0.01^{\circ} \mathrm{C}$.

\section{Results and discussion}

The relative viscosities and densities of the solutions of oxalic acid and its salts, viz. ammonium oxalate, sodium oxalate and potassium oxalate in water and in binary aqueous mixtures of THF [5, 10, 15 and $20 \%$ by weight of THF] were measured at $298 \cdot 15 \mathrm{~K}$. The experimental results of relative viscosities of oxalic acid and its salts in water and binary aqueous mixtures of THF have been analysed by the JonesDole equation ${ }^{28}$ :

$$
\eta_{\text {rel }}=\eta / \eta_{0}=1+A c^{1 / 2}+B c,
$$

where $\eta$ and $\eta_{0}$ are the viscosities of the solution and solvent (water, water $+\mathrm{THF}$ ) respectively, and $c$ is the molar concentration. $A$ and $B$ are the constants characteristic of solute-solute and solute-solvent interactions respectively.

The plots of $\left[\eta_{r}-1\right] / V_{c}$ versus $V_{c}$ for oxalic acid and its salts, were found to be linear, with least scatter in water and in different compositions of THF + water reported here. A representative plot for oxalic acid in different compositions of THF + water at $298.15 \mathrm{~K}$ is shown in figure 1 . The values of $A$ and $B$ parameters have been calculated using the least squares method by fitting the experimental results in the Jones-Dole equation and these values along with standard errors obtained in water and in different mixtures of tetrahydrofuran + water at $298.15 \mathrm{~K}$ are recorded in table 1 .

A perusal of table 1 shows that the values of $\mathrm{A}$ coefficients are positive and large in magnitude in water but reduce in magnitude considerably just on the addition of a small amount of THF and keep decreasing as the THF content increases and finally become negative, for oxalic acid and its salts at $298.15 \mathrm{~K}$, thereby showing that the solute-solute interactions which were quite strong in water have been reduced to weakened by the addition of THF to water. In other words, these results indicate that oxalic acid and its salts mix more ideally with THF + water as compared to water and there is a perfect solvation of oxalic acid and its salts in higher compositions of THF + water mixtures resulting in weak solute-solute interactions.

It is also evident from table 1 that the $B$-coefficients, are positive for oxalic acid and its salts in water and in binary aqueous mixtures of THF at also increases with the increase in THF composition in water suggesting that the solute-solvent interac-

Table 1. Values of $A$ and $B$ parameters of Jones-Dole equation for oxalic acid, ammonium oxalate, sodium oxalate and potassium oxalate in water and in different compositions of THF + water at $298 \cdot 15$ K. Standard errors are given in parentheses.

\begin{tabular}{lcc}
\hline $\begin{array}{l}\text { THF + water } \\
(\% \text { w/w })\end{array}$ & $\begin{array}{c}A \\
\left(\mathrm{dm}^{-3 / 2} \mathrm{~mol}^{-1 / 3}\right)\end{array}$ & $\begin{array}{c}B \\
\left(\mathrm{dm}^{3} \mathrm{~mol}^{-1}\right)\end{array}$ \\
\hline Oxalic acid & & \\
0 (water) & $2 \cdot 840(0 \cdot 013)$ & $0 \cdot 201(0 \cdot 001)$ \\
5 & $1 \cdot 328(0 \cdot 015)$ & $0 \cdot 243(0 \cdot 001)$ \\
10 & $0 \cdot 671(0 \cdot 016)$ & $0 \cdot 258(0 \cdot 001)$ \\
15 & $0 \cdot 014(0 \cdot 018)$ & $0 \cdot 274(0 \cdot 001)$ \\
20 & $-0.549(0 \cdot 026)$ & $0 \cdot 287(0 \cdot 001)$
\end{tabular}

Ammonium oxalate

$\begin{array}{lll}0(\text { water }) & 7.720(0.005) & 0.058(0.001) \\ 5 & 2.304(0.015) & 0.214(0.001) \\ 10 & 1.836(0.015) & 0.225(0.001) \\ 15 & 1.410(0.007) & 0.234(0.002) \\ 20 & 0.809(0.021) & 0.247(0.001)\end{array}$

Sodium oxalate

$\begin{array}{lll}0 \text { (water) } & 6.967(0.032) & 0.103(0.001) \\ 5 & 1.681(0.016) & 0.308(0.001) \\ 10 & -0.020(0.036) & 0.344(0.002) \\ 15 & -0.362(0.028) & 0.353(0.001) \\ 20 & -0.712(0.018) & 0.364(0.001)\end{array}$

Potassium oxalate

\begin{tabular}{lrl}
0 (water) & $10.995(0.016)$ & $0.177(0.001)$ \\
5 & $1.414(0.022)$ & $0.382(0.001)$ \\
10 & $0.538(0.025)$ & $0.401(0.001)$ \\
15 & $-0.405(0.017)$ & $0.425(0.001)$ \\
20 & $-2.213(0.019)$ & $0.468(0.001)$ \\
\hline
\end{tabular}


$298.15 \mathrm{~K}$, suggesting the presence of strong solutesolvent interactions. The value of the $B$-coefficient tions increase with the increase of THF in water for oxalic acid and its salts at $298 \cdot 15 \mathrm{~K}$, which result in the improvement of solute solvation. In other words, preferential solvation by THF molecules would also be expected to reduce the strong interactions of THF molecules with water, resulting in the increase in $\mathrm{B}$ values.

It is also clear from table 1 that the value of the $B$-coefficient is influenced to a considerable extent by the addition of $5 \%(\mathrm{w} / \mathrm{w})$ THF in water for individual solutes. In other words, the solvation of ions is greatly influenced in the presence of aqueo-organic medium as compared to aqueous medium. Since oxalate ion is common in all the three salts so from the values of B-coefficients it may be inferred that the $\mathrm{K}^{+}$ion is preferentially solvated by THF + water medium and the order of solvation is:

$$
\mathrm{K}^{+}>\mathrm{Na}^{+}>\mathrm{NH}_{4}^{+} .
$$

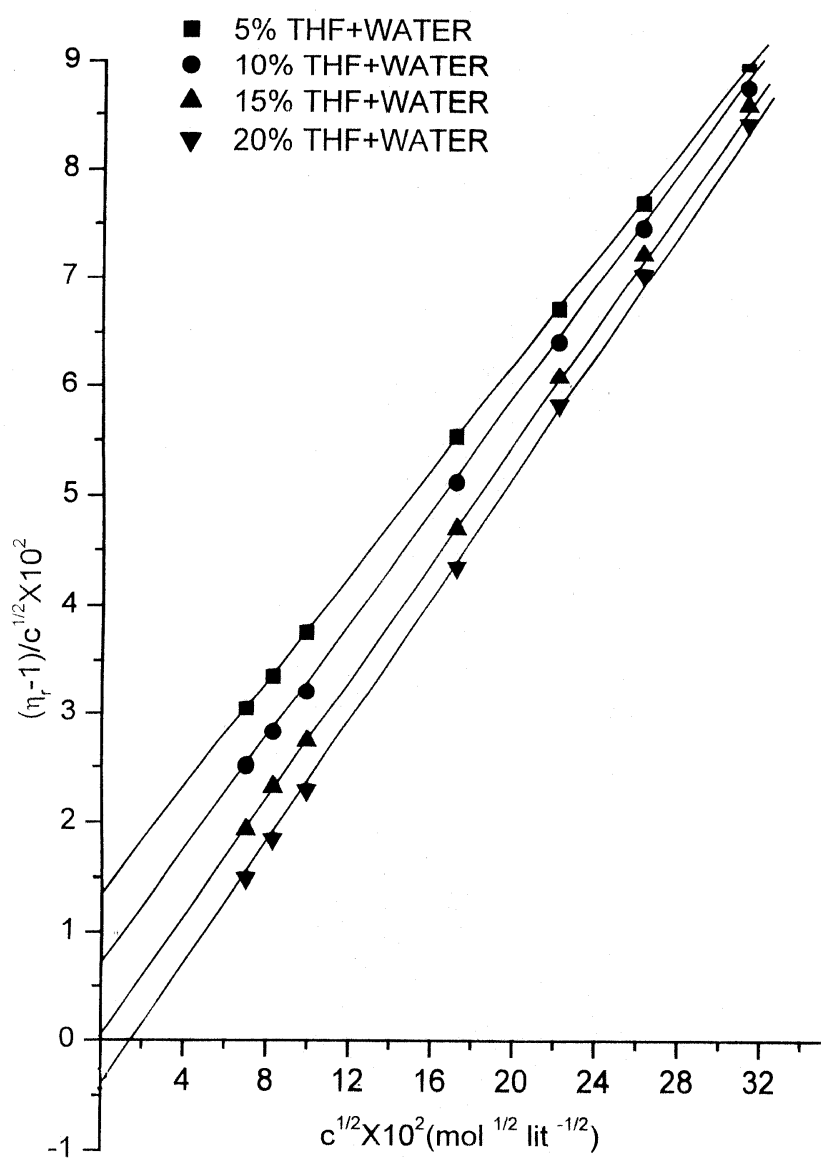

Figure 1. Plots of $\left(\eta_{r}-1\right) c^{1 / 2}$ vs $c^{1 / 2}$ for oxalic acid in different compositions of THF + water at $298 \cdot 15 \mathrm{~K}$.
The viscosity data have also been analysed on the basis of transition state treatment of relative viscosity as suggested by Feakins et al. ${ }^{29}$ The B parameter in terms of this theory is given by the following equation:

$$
B=\frac{\bar{V}_{1}^{0}-\bar{V}_{2}^{0}}{1000}+\frac{\bar{V}_{1}^{0}}{1000}\left[\frac{\Delta \mu_{2}^{0^{*}}-\Delta \mu_{1}^{0^{*}}}{R T}\right],
$$

where $\bar{V}_{1}^{0}$ is the mean volume of the solvent and $\bar{V}_{2}^{0}$ is the partial molar volume of the solute. The free energy of activation per mole of the pure solvent $\left(\ddot{A} \mu_{1}^{0 *}\right)$, and the free energy of activation per mole of solute $\left(\ddot{A} \mu_{2}^{0 *}\right)$ were calculated ${ }^{30}$ with the help of (3) and (4) respectively:

$$
\ddot{\mathrm{A}} \mu_{1}^{0 *}=R T \ln \left(\eta_{0} \bar{V}_{1}^{0} / h N\right),
$$

and

$$
\ddot{\mathrm{A}} \mu_{2}^{0 *}=\ddot{\mathrm{A}} \mu_{1}^{0 *}+R T / \bar{V}_{1}^{0}\left[1000 B-\left(\bar{V}_{1}^{0}-\bar{V}_{2}^{0}\right)\right]
$$

where $h$ is the Planck constant, $N$ the Avogadro number, $\eta_{0}$ the viscosity of solvent, $R$ the gas con-

Table 2. Values of $\bar{V}_{1}^{0}\left(\mathrm{dm}^{3} \mathrm{~mol}^{-1}\right), \bar{V}_{2}^{0}\left(\mathrm{dm}^{3} \mathrm{~mol}^{-1}\right), \ddot{A} \mu_{1}^{0 *}$

\begin{tabular}{|c|c|c|c|c|}
\hline \multirow[b]{2}{*}{ Parameter } & \multicolumn{4}{|c|}{$\mathrm{THF}+$ water $(\% \mathrm{w} / \mathrm{w})$} \\
\hline & 5 & 10 & 15 & 20 \\
\hline $\begin{array}{l}\bar{V}_{1}^{0} \\
\ddot{A}_{1}^{0} \mu_{1}^{*}\end{array}$ & $\begin{array}{l}18 \cdot 80 \\
21 \cdot 08\end{array}$ & $\begin{array}{l}19 \cdot 61 \\
21 \cdot 48\end{array}$ & $\begin{array}{l}20 \cdot 46 \\
21 \cdot 88\end{array}$ & $\begin{array}{l}21 \cdot 44 \\
22 \cdot 20\end{array}$ \\
\hline \multicolumn{5}{|l|}{ Oxalic acid } \\
\hline $\begin{array}{l}\bar{V}_{2}^{0} \\
\ddot{A}_{2}^{0} \mu_{2}^{*}\end{array}$ & $\begin{array}{r}103 \cdot 45 \\
64 \cdot 28\end{array}$ & $\begin{array}{r}109 \cdot 58 \\
65 \cdot 47\end{array}$ & $\begin{array}{r}115 \cdot 89 \\
66 \cdot 64\end{array}$ & $\begin{array}{r}124.98 \\
67 \cdot 35\end{array}$ \\
\hline \multicolumn{5}{|c|}{ Ammonium oxalate } \\
\hline $\begin{array}{l}\bar{V}_{2}^{0} \\
\ddot{A}_{\mu}^{0} \mu_{2}^{*}\end{array}$ & $\begin{array}{l}95 \cdot 23 \\
59 \cdot 37\end{array}$ & $\begin{array}{r}110 \cdot 76 \\
61.44\end{array}$ & $\begin{array}{r}117.04 \\
61.93\end{array}$ & $\begin{array}{r}125 \cdot 85 \\
62 \cdot 83\end{array}$ \\
\hline \multicolumn{5}{|c|}{ Sodium oxalate } \\
\hline $\begin{array}{l}\bar{V}_{2}^{0} \\
\ddot{A}_{\mu}^{0} \mu_{2}^{*}\end{array}$ & $\begin{array}{l}71 \cdot 23 \\
68 \cdot 60\end{array}$ & $\begin{array}{l}81 \cdot 36 \\
72 \cdot 77\end{array}$ & $\begin{array}{l}89 \cdot 53 \\
73 \cdot 02\end{array}$ & $\begin{array}{r}100 \cdot 73 \\
73 \cdot 45\end{array}$ \\
\hline \multicolumn{5}{|c|}{ Potassium oxalate } \\
\hline $\begin{array}{l}\bar{V}_{2}^{0} \\
\ddot{A}_{\mu}^{0} \mu_{2}^{0}\end{array}$ & $\begin{array}{l}67 \cdot 83 \\
78 \cdot 18\end{array}$ & $\begin{array}{l}79 \cdot 10 \\
79 \cdot 69\end{array}$ & $\begin{array}{l}88.41 \\
81 \cdot 60\end{array}$ & $\begin{array}{l}98 \cdot 60 \\
85 \cdot 23\end{array}$ \\
\hline
\end{tabular}
$\left(\mathrm{kJ} \mathrm{mol}^{-1}\right)$ and $\ddot{\mathrm{A}} \mu_{2}^{0} *\left(\mathrm{~kJ} \mathrm{~mol}^{-1}\right)$ for oxalic acid, ammonium oxalate, sodium oxalate and potassium oxalate in different compositions of THF + water at $298.15 \mathrm{~K}$. 
Table 3. Values of parameters $A\left(\mathrm{dm}^{3 / 2} \mathrm{~mol}^{-1 / 3}\right.$ and $B$ $\left(\mathrm{dm}^{3} \mathrm{~mol}^{-1}\right)$ of Jones-Dole equation for oxalic acid, ammonium oxalate, sodium oxalate and potassium oxalate in water and in $\mathrm{THF}+$ water $(5 \% \mathrm{w} / \mathrm{w})$ at different temperatures. Standard errors are given in parentheses.

\begin{tabular}{llllll}
\hline & \multicolumn{5}{c}{ Temperature (K) } \\
\cline { 2 - 6 } Parameters & $298 \cdot 15$ & $303 \cdot 15$ & $308 \cdot 15$ & $313 \cdot 15$ & $318 \cdot 15$
\end{tabular}

Water

Oxalic acid

$\begin{array}{cccccc}\text { A } & 2.840 & 2.211 & 1.296 & 0.159 & -0.325 \\ & (0.013) & (0.011) & (0.023) & (0.028) & (0.019) \\ \text { B } & 0.201 & 0.218 & 0.241 & 0.277 & 0.286 \\ & (0.001) & (0.001) & (0.001) & (0.001) & (0.002)\end{array}$

Ammonium oxalate

$\begin{array}{cccccc}\text { A } & 7.720 & 6.469 & 5.616 & 4.188 & 3.361 \\ & (0.005) & (0.026) & (0.015) & (0.031) & (0.016) \\ \text { B } & 0.058 & 0.090 & 0.112 & 0.154 & 0.177 \\ & (0.001) & (0.001) & (0.001) & (0.002) & (0.001)\end{array}$

Sodium oxalate

$\begin{array}{cccccc}\text { A } & 6.967 & 5.301 & 4.618 & 4.035 & 3.039 \\ & (0.032) & (0.019) & (0.019) & (0.019) & (0.015) \\ \text { B } & 0.103 & 0.152 & 0.171 & 0.187 & 0.214 \\ & (0.001) & (0.001) & (0.001) & (0.001) & (0.002)\end{array}$

Potassium oxalate

$\begin{array}{cccccc}\text { A } & 10.995 & 9.938 & 9.448 & 6.850 & 6.248 \\ & (0.016) & (0.023) & (0.042) & (0.027) & (0.045) \\ \text { B } & 0.177 & 0.206 & 0.251 & 0.289 & 0.305 \\ & (0.001) & (0.001) & (0.002) & (0.001) & (0.002)\end{array}$

$5 \%(w / w) T H F+$ water

Oxalic acid

$\begin{array}{cccccc}\text { A } & 1.328 & 0.829 & 0.239 & -0.056 & -0.913 \\ & (0.015) & (0.019) & (0.024) & (0.013) & (0.015) \\ \text { B } & 0.243 & 0.255 & 0.270 & 0.277 & 0.304 \\ & (0.001) & (0.001) & (0.002) & (0.001) & (0.001)\end{array}$

Ammonium oxalate

$\begin{array}{cccccc}\text { A } & 2.304 & 1.773 & 0.283 & -0.165 & -0.462 \\ & (0.015) & (0.018) & (0.017) & (0.020) & (0.028) \\ \text { B } & 0.214 & 0.229 & 0.271 & 0.284 & 0.290 \\ & (0.001) & (0.001) & (0.001) & (0.002) & (0.001)\end{array}$

Sodium oxalate

\begin{tabular}{|c|c|c|c|c|c|}
\hline $\mathrm{A}$ & $1 \cdot 681$ & $1 \cdot 196$ & $0 \cdot 396$ & $-0 \cdot 344$ & $-1 \cdot 272$ \\
\hline & $(0 \cdot 016)$ & $(0 \cdot 020)$ & $(0 \cdot 024)$ & $(0 \cdot 008)$ & $(0.016)$ \\
\hline B & $0 \cdot 308$ & $0 \cdot 320$ & $0 \cdot 341$ & $0 \cdot 362$ & $0 \cdot 376$ \\
\hline & $(0 \cdot 001)$ & $(0 \cdot 001)$ & $(0 \cdot 001)$ & $(0 \cdot 001)$ & $(0.002)$ \\
\hline \multicolumn{6}{|c|}{ Potassium oxalate } \\
\hline \multirow[t]{2}{*}{ A } & 1.414 & 0.973 & $0 \cdot 050$ & -0.425 & $-3 \cdot 268$ \\
\hline & $(0 \cdot 022)$ & $(0 \cdot 035)$ & $(0 \cdot 021)$ & $(0.024)$ & $(0.030)$ \\
\hline \multirow[t]{2}{*}{$\mathrm{B}$} & $0 \cdot 383$ & $0 \cdot 389$ & 0.413 & 0.425 & 0.512 \\
\hline & $(0 \cdot 001)$ & $(0 \cdot 002)$ & $(0 \cdot 001)$ & $(0 \cdot 001)$ & $(0 \cdot 002)$ \\
\hline
\end{tabular}

stant and $T$ the absolute temperature. The values of $\ddot{\mathrm{A}} \mu_{1}^{0} *$ calculated from (3) are given in table 2 .

For mixed solvents, each solvent mixture was treated as pure and the molar volume taken as a mean volume defined ${ }^{12}$ as:

$$
\bar{V}_{1}^{0}=\left[x_{1} M_{1}+x_{2} M_{2}\right] / d_{1},
$$

where $x_{1}, M_{1}$ and $x_{2}, M_{2}$ are the mole fractions, and molecular weights of water and THF respectively, and $d_{1}$ is the density of solvent (THF + water). The values of $\bar{V}_{2}^{0}$, the partial molar volumes at infinite dilution for oxalic acid and its salts, determined from density data, are also recorded in table 2 . The values of $\ddot{A} \mu_{2}^{0} *$ and $\bar{V}_{1}^{0}$, calculated with the help of (4) and (5) respectively, are also recorded in table 2.

It is evident from the data (table 2) that $\ddot{\mathrm{A}} \mu_{1}^{0} *$ is practically constant at all solvent compositions implying that $\ddot{\mathrm{A}} \mu_{2}^{0} *$ is dependent mainly on $B$ coefficient and $\left(\bar{V}_{1}^{0}-\bar{V}_{2}^{0}\right)$ terms. It is also clear from table 2 that the values of $\ddot{\mathrm{A}} \mu_{2}^{0} *$ are positive and larger than $\ddot{\mathrm{A}} \mu_{1}^{0} *$ which suggest that the formation of the transition state is less favoured in the presence of oxalic acid and its salts, meaning thereby that the formation of transition state is accompanied by the breaking and distortion of the intermolecular bonds between THF and water, i.e. solvent.

Recently, it has been emphasized by many workers that $\mathrm{d} B / \mathrm{d} T$ is a better criterion ${ }^{31}$ for determining the structure making/breaking nature of any solute than simply the $B$ coefficient. So this means that in order to follow this criterion, the temperature effect must be studied.

\subsection{Effect of temperature}

Because of the identical behaviour of oxalic acid and an individual salt in different compositions of $\mathrm{THF}+$ water at $298 \cdot 15 \mathrm{~K}$, the effect of temperature has been studied in water and only in $5 \%(\mathrm{w} / \mathrm{w})$ $\mathrm{THF}+$ water. The plots of $\left[\eta_{r}-1\right] / \sqrt{ }_{c}$ versus $\sqrt{ }_{c}$ have been found to be linear at 298.15, 303.15, 308.15, $313 \cdot 15$ and $318 \cdot 15 \mathrm{~K}$ in accordance with the JonesDole equation, (1), for oxalic acid, ammonium oxalate, sodium oxalate and potassium oxalate. A sample plot for oxalic acid is shown in figure 2 at different temperatures. Values of $A$ and $B$ parameters have been calculated using the least squares method and these values, along with standard errors, are recorded in table 3 .

It is evident from table 3 that the values of $A$ coefficient are either positive or negative for oxalic 


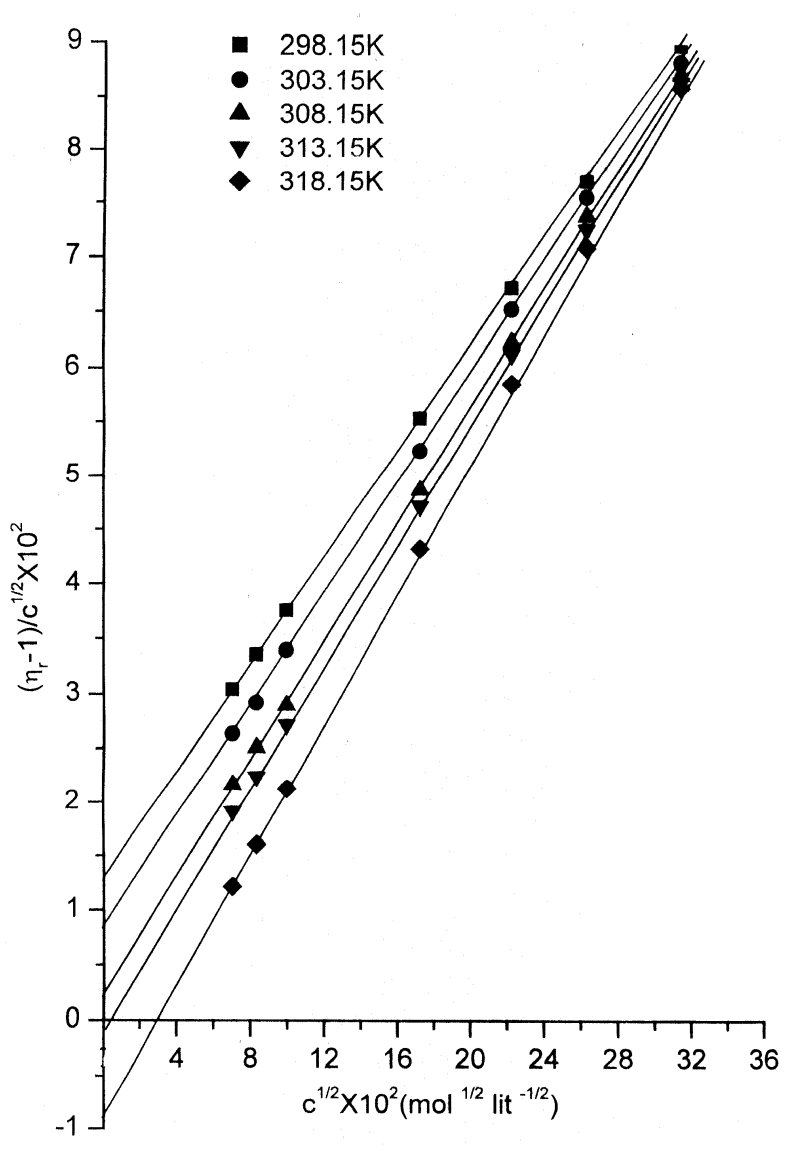

Figure 2. Plots of $\left(\eta_{r}-1\right) c^{1 / 2}$ vs $c^{1 / 2}$ for oxalic acid in $5 \%$ $(\mathrm{w} / \mathrm{w}) \mathrm{THF}+$ water at different temperatures.

Table 4. Values of $\bar{V}_{1}^{0}\left(\mathrm{dm}^{3} \mathrm{~mol}^{-1}\right), \bar{V}_{2}^{0}\left(\mathrm{dm}^{3} \mathrm{~mol}^{-1}\right), \ddot{A} \mu_{1}^{0} *$ $\left(\mathrm{kJ} \mathrm{mol}^{-1}\right)$ and $\ddot{\mathrm{A}} \mu_{2}^{0} *\left(\mathrm{~kJ} \mathrm{~mol}^{-1}\right)$ for oxalic acid, ammonium oxalate, sodium oxalate and potassium oxalate in $\mathrm{THF}+$ water $(5 \% \mathrm{w} / \mathrm{w})$ at different temperatures.

\begin{tabular}{|c|c|c|c|c|c|}
\hline \multirow[b]{2}{*}{ Parameters } & \multicolumn{5}{|c|}{ Temperature (K) } \\
\hline & $298 \cdot 15$ & $303 \cdot 15$ & $308 \cdot 15$ & $313 \cdot 15$ & $318 \cdot 15$ \\
\hline $\bar{V}_{1}^{0}$ & $18 \cdot 80$ & $18 \cdot 83$ & $18 \cdot 87$ & $18 \cdot 91$ & $18 \cdot 92$ \\
\hline$\ddot{A} \mu_{1}^{0} *$ & $21 \cdot 08$ & $21 \cdot 09$ & $21 \cdot 16$ & $21 \cdot 13$ & $21 \cdot 29$ \\
\hline \multicolumn{6}{|l|}{ Oxalic acid } \\
\hline & $103 \cdot 45$ & $111 \cdot 44$ & $117 \cdot 05$ & $120 \cdot 85$ & $128 \cdot 09$ \\
\hline$\ddot{\mathrm{A}} \mu_{2}^{0} *$ & $64 \cdot 28$ & $67 \cdot 62$ & $71 \cdot 14$ & $73 \cdot 40$ & $79 \cdot 05$ \\
\hline \multicolumn{6}{|c|}{ Ammonium oxalate } \\
\hline $\bar{V}_{2}^{0}$ & $95 \cdot 23$ & $102 \cdot 42$ & $108 \cdot 39$ & $114 \cdot 74$ & $123 \cdot 51$ \\
\hline$\ddot{\mathrm{A}} \mu_{2}^{0} *$ & $59 \cdot 37$ & $62 \cdot 93$ & $70 \cdot 10$ & $73 \cdot 52$ & $76 \cdot 74$ \\
\hline \multicolumn{6}{|c|}{ Sodium oxalate } \\
\hline $\bar{V}_{2}^{0}$ & $71 \cdot 23$ & $80 \cdot 17$ & $86 \cdot 40$ & $93 \cdot 45$ & $104 \cdot 41$ \\
\hline $\mathrm{A} \mu_{2}^{*}$ & $68 \cdot 60$ & $72 \cdot 13$ & $76 \cdot 63$ & $81 \cdot 33$ & $86 \cdot 09$ \\
\hline \multicolumn{6}{|c|}{ Potassium oxalate } \\
\hline $\bar{V}_{2}^{0}$ & $68 \cdot 85$ & $75 \cdot 03$ & $81 \cdot 35$ & $88 \cdot 02$ & $97 \cdot 12$ \\
\hline$\ddot{\mathrm{A}} \mu_{2}^{0} *$ & $78 \cdot 18$ & $80 \cdot 68$ & $85 \cdot 71$ & $89 \cdot 26$ & $92 \cdot 60$ \\
\hline
\end{tabular}

acid and its individual salt in water as well as in $\mathrm{THF}+$ water $(5 \% \mathrm{w} / \mathrm{w})$ mixture and continuously decrease with rise in temperature, thereby suggesting that solute-solute interactions are weakened with increase of temperature. In other words it may be said that with rise in temperature the solvation of oxalic acid and an individual salt is enhanced.

The values of $B$ coefficient are positive for oxalic acid and its salts in water and in $\mathrm{THF}+$ water $(5 \%$ w/w) at all temperatures, showing the presence of strong solute-solvent interactions. Further, the value of the $B$ coefficient increases with rise in temperature which suggests that solute-solvent interactions are strengthened with rise in temperature for oxalic acid and its salts in water and $\mathrm{THF}+$ water.

The value of $\mathrm{d} B / \mathrm{d} T$ is positive for oxalic acid, ammonium oxalate, sodium oxalate and potassium oxalate in water as well as in $\mathrm{THF}+$ water showing that oxalic acid and its salts act as structure breakers in both the systems.

The data for viscosity $B$ coefficient at different temperatures have also been analysed by applying the transition state theory. The values of $\ddot{\mathrm{A}} \mu_{1}^{0} *$ and $\ddot{\mathrm{A}} \mu_{2}^{0} *$ have been calculated with the help of (3) and (4) respectively, and are recorded in table 4.

According to Feakins model, ${ }^{29} \ddot{\mathrm{A}} \mu_{2}^{0 *}$ increases with temperature for solutes having positive values of $\mathrm{d} B / \mathrm{d} T$. This is nicely shown by oxalic acid and its

Table 5. Entropy, $T \ddot{\mathrm{A}} S_{2}^{0} *\left(\mathrm{~kJ} \mathrm{~mol}^{-1}\right)$ and enthalpy, $\ddot{\mathrm{A}} H_{2}^{0} *$ $\left(\mathrm{kJ} \mathrm{mol}^{-1}\right)$ of activation for viscous flow of oxalic acid, ammonium oxalate, sodium oxalate and potassium oxalate in $\mathrm{THF}+$ water $(5 \% \mathrm{w} / \mathrm{w})$ at different temperatures.

\begin{tabular}{llllll}
\hline & \multicolumn{5}{c}{ Temperature (K) } \\
\cline { 2 - 6 } Parameters & $298 \cdot 15$ & $303 \cdot 15$ & $308 \cdot 15$ & $313 \cdot 15$ & $318 \cdot 15$ \\
\hline Oxalic acid & & & & & \\
$T \ddot{\mathrm{A}} S_{2}^{0}$ & $-210 \cdot 49$ & -214.02 & -217.55 & -221.08 & -224.61 \\
$\mathrm{~A} H_{2}^{0^{*}}$ & $-146 \cdot 21$ & -146.40 & -146.41 & -147.68 & -145.56
\end{tabular}

Ammonium oxalate

$T \ddot{A} S_{2}^{0} * \quad-270.42 \quad-274.96-279.49-284.03-288.56$

$\begin{array}{llllll}\ddot{\mathrm{A}} H_{2}^{0} * & -211.05 & -212.03 & -209.39 & -210.51 & -211.82\end{array}$

Sodium oxalate

$T \ddot{\mathrm{A}} \mathrm{S}_{2}^{0} * \quad-263.56 \quad-267.98-272.40-276.82-281.24$

$\ddot{\mathrm{A}} H_{2}^{0} * \quad-194.96 \quad-195.85-195.77-195.49-195.15$

Potassium oxalate

$T \ddot{\mathrm{A}} \mathrm{S}_{2}^{0 *} \quad-360 \cdot 17-366 \cdot 21-372.25-378.29-384.33$

$\begin{array}{llllll}\ddot{\mathrm{A}} H_{2}^{0} * & -281.99 & -285.53 & -286.54 & -289.03 & -280.25\end{array}$ 


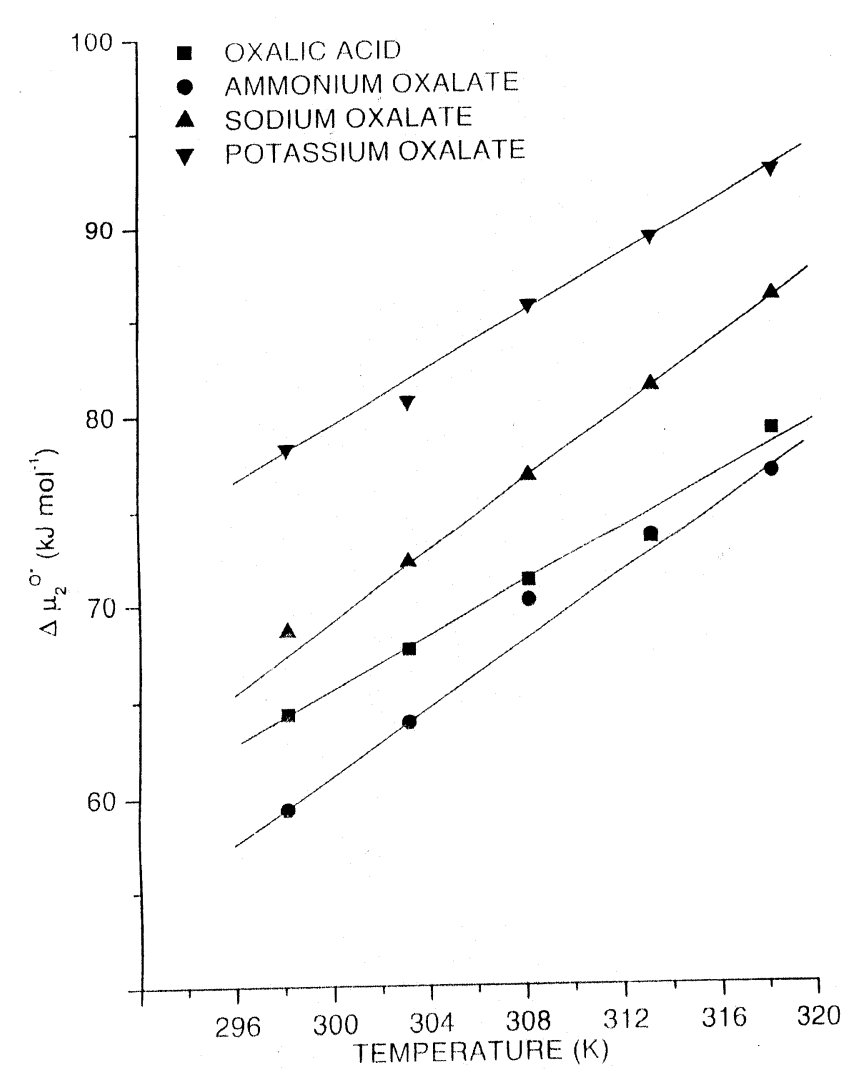

Figure 3. Variation of $\ddot{\mathrm{A}} \mu_{2}^{0} *$ with temperature for oxalic acid, ammonium oxalate, sodium oxalate and potassium oxalate in $5 \%(\mathrm{w} / \mathrm{w}) \mathrm{THF}+$ water.

salts, which act as structure breakers in water as well as in THF + water.

It is also evident from table 4 that the quantity $\left(\ddot{\mathrm{A}} \mu_{2}^{0 *}-\ddot{\mathrm{A}} \mu_{1}^{0 *}\right)$, the change in activation energy per mole of solute on replacing one mole of solvent by one mole of solute at infinite dilution, is positive and large for oxalic acid and its salts studied in 5\% (w/w) THF + water at different temperatures, therefore it may be concluded from these data that the formation of the transition state is accompanied by breaking/distortion of the intermolecular bonds of the solvent. In other words, the formation of the transition state is less favoured in the presence of oxalic acid and its salts in the entire temperature range.

The activation entropy for oxalic acid and its salts has also been calculated from the following relation ${ }^{29}$ :

$$
\mathrm{d}\left(\ddot{\mathrm{A}} \mu_{2}^{0 *}\right) / \mathrm{d} T=-\ddot{\mathrm{A}} S_{2}^{0 *} .
$$

The values of $\ddot{\mathrm{A}} S_{2}^{0 *}$ have been calculated from the slopes of linear plots of $\ddot{A} \mu_{2}^{0 *}$ versus $T$, shown in figure 3 , by using the least squares method. The values of $T \ddot{A} S_{2}^{0 *}$ at different temperatures are listed in table 5. The activation enthalpy $\left(\ddot{\mathrm{A}} H_{2}^{0} *\right.$ ) has been calculated with the help of following expression ${ }^{29}$ :

$$
\ddot{\mathrm{A}} H_{2}^{0 *}=\ddot{\mathrm{A}} \mu_{2}^{0} *+T \ddot{\mathrm{A}} S_{2}^{0 *},
$$

and the values are also recorded in table 5 .

It is evident from table 5 that both enthalpy and entropy of activation are negative for oxalic acid and its salts viz. ammonium oxalate, sodium oxalate and potassium oxalate, in 5\% (w/w) THF + water mixture at different temperatures, which suggest that the transition state is associated with bond-breaking and increase in order. Although a detailed mechanism for this cannot be easily advanced, it may be suggested that the slip-plane is in the disordered state.

\section{Acknowledgement}

One of the authors (MKG) is grateful to the Council of Scientific and Industrial Research, New Delhi for a fellowship.

\section{References}

1. Wadi R K and Goyal R K 1992 J. Soln. Chem. 21 163

2. Parmar M L, Rao Ch V N and Bhardwaj S K 1992 Indian J. Chem. A31 716

3. Pandey J D, Jain P and Vyas V 1994 Can. J. Chem. 721486

4. Parmar M L and Chauhan M K 1995 Indian J. Chem. A34 434

5. Jauhar S P, Markandeya B and Kapila V P 1997 Indian J. Chem. A36 898

6. Parmar M L and Sharma S 1998 Res. J. Chem. Environ. 217

7. Pandey J D, Akhtar Y and Sharma A K 1998 Indian J. Chem. A37 1094

8. Parmar M L 1998 J. Indian Council. Chem. 1510

9. Mishra A P and Gautam S K 2001 Indian J. Chem. A40 100

10. Parmar M L 2002 J. Indian Council. Chem. 1924

11. Kipkemboi P K and Easteal A J 2002 Indian J. Chem. A41 1139

12. Parmar M L, Dhiman D K and Thakur R C 2002 Indian J. Chem. A41 2032

13. Das D, Das B and Hazra D K 2002 J. Soln. Chem. 31 425

14. Das D, Das B and Hazra D K 2003 J. Soln. Chem. 32 77

15. Das D, Das B and Hazra D K 2003 J. Soln. Chem. 32 85

16. Choudhury A, Jha A and Roy M N 2003 J. Indian Chem. Soc. 80632

17. Parmar M L, Awasthi R K and Guleria M K 2004 Indian J. Chem. A43 41 
18. Das D and Hazra D K 2004 Indian J. Chem. A43 505

19. Mishra A P 2004 Indian J. Chem. A43 730

20. Tsierkezos and Molinou L E 2004 Z. Phys. Chem. 218211

21. Inove $\mathrm{N}, \mathrm{Xu} \mathrm{M}$ and Petrucci 1987 J. Phys. Chem. 91 4628

22. Covington A K and Dickinson T (eds) 1973 Physical chemistry of organic solvent systems (New York: Plenum) p. 5

23. Shoemaker D P and Garland C W 1967 Experiments in physical chemistry (New York: McGraw Hill) p. 131

24. Ward G K and Millero F J 1974 J. Soln. Chem. 3417
25. Parmar M L and Dhiman D K 2001 Indian J. Chem. A40 1161

26. Parmar M L, Khanna A and Gupta V K 1989 Indian J. Chem. A28 565

27. Parmar M L and Rao Ch V N 1990 Indian J. Chem. A29 958

28. Jones G and Dole M 1929 J. Am. Chem. Soc. 512950

29. Feakins D, Freemental J D and Lawrence K G 1974 J. Chem. Soc., Faraday Trans. I 70795

30. Glasstone S, Laidler K and Eyring H 1941 The theory of rate processes (New York: McGraw Hill) p. 477

31. Sarma T S and Ahluwalia J C 1973 Rev. Chem. Soc. 2217 